\title{
Gastric Diffuse Large B-Cell Lymphoma: A Single-Center 9-Year Experience
}

\author{
Maria Eduarda Couto ${ }^{1}$ (i) $\cdot$ Isabel Oliveira ${ }^{1} \cdot$ Nelson Domingues $^{1} \cdot$ Luísa Viterbo $^{1}$. \\ Ângelo Martins $^{1} \cdot$ Illídia Moreira $^{1} \cdot$ Ana Espírito-Santo $^{1} \cdot$ Sérgio Chacim $^{1}$. \\ Cláudia Moreira $^{1} \cdot$ Dulcineia Pereira $^{1} \cdot$ Rui Henrique $^{2,3} \cdot$ José Mariz $^{1}$
}

Received: 28 August 2020/Accepted: 27 November 2020/Published online: 2 January 2021

(C) Indian Society of Hematology and Blood Transfusion 2021

\begin{abstract}
Gastric diffuse large B cell lymphoma (DLBCL) represents the majority of all gastric lymphomas. We report a series of gastric DLBCL diagnosed and treated in a single center, between 2010 and 2018 (included). We retrospectively analyzed the population demographic features, treatment outcomes and survival. One-hundred-and-one patients were studied, $50.5 \%$ males and median age of 64 years [23-94]. Lugano staging was I in $16.8 \%$, II1 in $20.8 \%$, II2 in $10.9 \%$, IIE in $13.9 \%$ and IV in $34.7 \%$ of cases. Twenty percent had Helicobacter pylori infection. R-CHOP-like therapy was used as first line in $96.9 \%$ of the patients. A complete response was achieved in $80 \%$ after first line therapy. At 3-years of follow-up (FU), 54\% were in complete remission. The mean $\mathrm{FU}$ time was 73.6 months. Median overall survival and median progression free survival were not reached. We identified seven factors with negative impact in survival: age above 65 years-old $(p<0.01)$, ECOG $2-3(p<0.01)$, B symptoms $(p=0.001)$, bulky disease $(p=0.003)$, IPI $3-4$ $(p=0.001)$, more than 3 treatment lines $(p<0.01)$, absence of response to first line treatment $(p<0.01)$. This study demonstrates that gastric DLBCL is a potentially curable disease with R-CHOP-like therapy, entailing long
\end{abstract}

Maria Eduarda Couto

i2434@ipoporto.min-saude.pt

1 Department of Onco-hematology, Portuguese Oncology Institute of Porto (IPO-Porto), Porto, Portugal

2 Department of Pathology and Cancer Biology and Epigenetics Group - Research Centre (CI-IPOP), Portuguese Oncology Institute of Porto (IPO-Porto), Porto, Portugal

3 Department of Pathology and Molecular Immunology, Institute of Biomedical Sciences Abel Salazar (ICBAS), University of Porto, Porto, Portugal term survival and comparing well with other published series.

Keywords Aggressive - Non-Hodgkin's lymphoma . Rituximab · Gastric

\section{Introduction}

Gastric diffuse large B cell lymphoma (DLBCL) represents nearly $59 \%$ of all gastric lymphomas [1]. It may arise primarily or owing to transformation of a low grade lymphoma, most frequently Mucosa Associated Lymphoid Tissue (MALT)-type, being relevant risk factors chronic gastritis and Helicobacter pylori infection [2-5].

Clinical symptoms are usually unspecific and more suggestive of chronic gastritis, which might delay the diagnosis [6]. Invasion of the central nervous system is unusual. Treatment commonly entails chemotherapy (RCHOP-like: rituximab, cyclophosphamide, vincristine, doxorubicin, prednisolone), with radiotherapy for localized stages, achieving long term success [7, 8].

There are no defined prognostic markers for this disease. However, large series suggest that bulky mass, advanced stage, aggressive histology, B symptoms, high $\beta 2$-microglobulin and serum LDH levels might be relevant [1].

Therefore, we report the experience of a single, tertiary, Portuguese center on gastric DLBCL over a period of nine years, providing a retrospective analysis of the population demographic features, treatment outcomes and survival. 


\section{Methods}

All gastric DLBCL diagnosed in patients older than 18 years and treated in one oncologic center between 2010 and 2018 were reviewed until March 2020. The diagnosis was defined by pathological confirmation in a gastric biopsy (according to World Health Organization guidelines) and for having the largest tumor mass located in this region [9]. The Lugano staging system was used for stratification [10]. Risk classification was also performed according to the International Prognostic Index (IPI) [11]. A descriptive statistics and survival (Kaplan-Meier method) were performed, with search for prognostic factors that could influence survival (applying the log-rank test for each marker; $p<0.05$ was considered significant).

\section{Results}

\section{Patient's Characteristics}

A total of 101 caucasian patients were analyzed, with a slight predominance of the male gender and a median age of 64 years. The most common symptoms were retrosternal burn (68.3\%), weight loss (38.6\%) and early satiety (28.7\%). The demographic and pathologic features of these patients at the diagnosis are depicted in Table 1.

\section{Treatment Strategies and Outcomes}

Chemotherapy was prescribed in $97 \%$ of the patients (3 patients were not eligible) and $77.6 \%$ were only exposed to first line (Table 2). The R-CHOP-like treatment was used as first line treatment in $96.9 \%$ of the patients. Our routine practice for localized disease included radiotherapy associated with first line in $51 \%$ of the cases. A complete response was obtained in $80 \%$ of patients, a partial response in $2 \%$, disease progression in $9 \%$, relapse in $8 \%$ and $9 \%$ were not evaluated after first line.

Antibiotic schemes for $H$. pylori eradication were prescribed for all infected cases $(20 \%)$.

Four patients died with disease before a second line therapy, which was prescribed in 14 cases $(6$ of them for relapse). Third and fourth lines were prescribed in 5 and 2 cases, respectively.

The most common complications along treatment were infectious. There were 2 cases of upper gastrointestinal bleeding, 2 gastrointestinal perforations, 3 stenosis (pyloric and esophageal).

Thirteen patients were submitted to surgery: 5 at diagnosis; the others for pyloric stenosis after chemotherapy (1), suspicion of resistant disease (1), gastric perforation
Table 1 Demographic features of the patient population

\begin{tabular}{|c|c|}
\hline & Total \\
\hline Median age [range] (y) & 64 [23-94] \\
\hline Male, n (\%) & $51(50.5 \%)$ \\
\hline \multicolumn{2}{|l|}{ Lugano staging system, n (\%) } \\
\hline I & $17(16.8 \%)$ \\
\hline II1 & $21(20.8 \%)$ \\
\hline II 2 & $11(10.9 \%)$ \\
\hline IIE & $14(13.9 \%)$ \\
\hline IV & $35(34.7 \%)$ \\
\hline Unknown & $3(3 \%)$ \\
\hline \multicolumn{2}{|l|}{ International Prognostic Index (IPI) score, n (\%) } \\
\hline IPI $0-1$ & 45 \\
\hline IPI $2-3$ & 42 \\
\hline IPI 4-5 & 11 \\
\hline IPI unknown & 3 \\
\hline \multicolumn{2}{|l|}{ Transformed histology, n (\%) } \\
\hline Follicular lymphoma transformed & $2(2 \%)$ \\
\hline MALT lymphoma transformed & $5(5 \%)$ \\
\hline \multicolumn{2}{|l|}{ Cell of origin according to the Hans algorithm, n (\%) } \\
\hline Non-GC & $54(53 \%)$ \\
\hline GC & $39(39 \%)$ \\
\hline Cell of origin unknown & $8(8 \%)$ \\
\hline Double expression (Bcl-2, Bcl-6 or MYC), n (\%) & $30(30 \%)$ \\
\hline B symptoms, n (\%) & $28(27.7 \%)$ \\
\hline Bulky mass $(>10 \mathrm{~cm}), \mathrm{n}(\%)$ & $11(10 \%)$ \\
\hline CNS involvement, $\mathrm{n}(\%)$ & $3(3 \%)$ \\
\hline Bone marrow involvement, $\mathrm{n}(\%)$ & $4(4 \%)$ \\
\hline High LDH, n (\%) & $41(40 \%)$ \\
\hline Median serum albumin $(\mathrm{n}=91)$, range 37 & {$[17-52.2]$} \\
\hline High $\beta 2$-microglobulin, n (\%) & $10(10 \%)$ \\
\hline H. pylori infection, n (\%) & $20(20 \%)$ \\
\hline Median ECOG, range & $0[0-4]$ \\
\hline Median BSA, $\mathrm{n}=75$, range & $1.78[1.29-2.28]$ \\
\hline Median BMI, $\mathrm{n}=75$, range & $26[16.02-46.41]$ \\
\hline Another gastric neoplasia, n (\%) & $1(1 \%)$ \\
\hline
\end{tabular}

BSA Body surface area (DuBois \& DuBois formula), BMI Body mass index, CNS Central nervous system, ECOG Eastern cooperative oncology group, $L D H$ Lactate dehydrogenase, $G C$ Germinal center, H. pylori Helicobacter pylori, MALT Mucosal associated lymphoid tissue, Non-GC Non-germinal center

after chemotherapy (1), secondary adenocarcinoma (1), secondary GIST (1), extraction of a gastric prosthesis (1), drainage of a gastro-pancreatic fistula (1) and extensive disease (1).

There were 2 cases submitted to autologous HSCT: 1 in first line and another one in third line for consolidation. There were other cases proposed but not submitted to transplant at the end of this study (due to disease relapse, epidemiologic context of SARS-CoV2 and death). 
Table 2 Chemotherapy and radiotherapy schemes prescribed as well as the complete responses obtained in all treatment lines

\begin{tabular}{|c|c|c|c|c|c|c|c|c|}
\hline \multirow[t]{2}{*}{ Treatment options } & \multicolumn{2}{|c|}{ 1st line $(n=98)$} & \multicolumn{2}{|c|}{ 2nd line $(n=14)$} & \multicolumn{2}{|c|}{ 3rd line $(n=5)$} & \multicolumn{2}{|c|}{ 4th line $(n=2)$} \\
\hline & $\mathrm{n}(\%)$ & $\mathrm{CR}, \mathrm{n}(\%)$ & $\mathrm{n}(\%)$ & $\mathrm{CR}, \mathrm{n}(\%)$ & $\mathrm{n}(\%)$ & $\mathrm{CR}, \mathrm{n}(\%)$ & $\mathrm{n}(\%)$ & $\mathrm{CR}, \mathrm{n}(\%)$ \\
\hline $\mathrm{R}-\mathrm{CHOP}+\mathrm{RT}$ & $46(46.9)$ & $44(95.7)$ & & & & & & \\
\hline R-CHOP & $39(39.8)$ & $28(71.8)$ & & & & & & \\
\hline CHOP & $3(3.1)$ & $1(33.3)$ & & & & & & \\
\hline R-CHOEP + RT & $2(2)$ & $2(100)$ & & & & & & \\
\hline R-CHOP followed by R-CHOEP & $2(2)$ & $1(50)$ & & & & & & \\
\hline R-CHOP followed by R-CHOEP + RT & $1(1)$ & 0 & & & & & & \\
\hline R-CHOEP & $1(1)$ & $1(100)$ & & & & & & \\
\hline R-CHOP followed by AHSCT & $1(1)$ & 0 & & & & & & \\
\hline Vincristine followed by MPD & $1(1)$ & 0 & & & & & & \\
\hline Total gastrectomy and R-CHOP & $1(1)$ & $1(100)$ & & & & & & \\
\hline RT (1 palliative patient) & $1(1)$ & 0 & $1(7.1)$ & 0 & & & & \\
\hline (R)ICE & & & $5(35.7)$ & $2(40)$ & & & & \\
\hline PEPC & & & $2(14.3)$ & 0 & & & & \\
\hline (R)MINE & & & $2(14.3)$ & $1(50)$ & & & & \\
\hline Maintenance with LD & & & $1(7.1)$ & $1(50)$ & & & & \\
\hline R-MPV & & & $1(7.1)$ & 0 & & & & \\
\hline R-ICE + R-DHAP & & & $1(7.1)$ & 0 & & & & \\
\hline R-DHAP & & & $1(7.1)$ & 0 & & & & \\
\hline DHAP & & & & & $1(20)$ & 0 & & \\
\hline ICE & & & & & $1(20)$ & 0 & & \\
\hline Total gastrectomy Roux y + AHSCT & & & & & $1(20)$ & $1(100)$ & & \\
\hline Clinical Assay & & & & & $1(20)$ & 0 & & \\
\hline PEPC & & & & & $1(20)$ & 0 & $1(50)$ & 0 \\
\hline Antalgic RT + Lenalidomide & & & & & & & $1(50)$ & 0 \\
\hline
\end{tabular}

AHSCT Autologous hematopoietic stem cell transplant, $C R$ Complete response, $L D$ Lenalidomide and dexamethasone, $M P D$ Methylprednisolone, $P E P C$ Prednisone, etoposide, procarbazine, cyclophosphamide, $R$-CHOP Rituximab, cyclophosphamide, vincristine, doxorubicin and prednisolone, $R$-CHOEP R-CHOP and etoposide, $(R)$-DHAP (Rituximab)-dexamethasone, cytarabine, cisplatin, $(R)-I C E$ (Rituximab)-ifosfamide, carboplastine and etoposide, (R)-MINE (Rituximab)-mesna, ifosfamide, metoxantrone, etoposide, $R$ - $M P V$ Rituximab, methotrexate, leucovorin, procarbazine, vincristine, $R T$ Radiotherapy

\section{Survival Analysis and Prognostic Factors}

The median FU time was 73.6 months (95\% CI: [66-88]). At 3 year-FU time $61.4 \%$ of the patients were alive. The median overall survival (OS) and median progression free survival (PFS) times were not reached. The mean OS time was 73.6 months (95\% CI: [66-81], Fig. 1) and the mean PFS time was 64.8 months (95\% CI: [56.3-73.5]). There were 27 deaths: 3 in patients not treated, 6 without disease (after first line) and 18 in relapse (12 after first line and 2 after each subsequent line).

An univariate analysis searching for factors with negative impact in survival was performed using log-rank (mantel-cox) test. Age above 65 years-old $(p<0.01)$, ECOG $\geq 2(p<0.01)$, B symptoms $(p=0.001)$, bulky disease $(p=0.003)$, IPI $\geq 3(p=0.001)$, more than 3 lines of treatment $(p<0.01)$, absence of response to first line treatment $(p<0.01)$ were disclosed as indicative of adverse prognosis. All other factors analyzed in our population had no impact on survival. There was progression after first line therapy or death caused by the disease in 35 patients, in a median time of 4 months [0-11].

\section{Discussion}

Gastric DLBCL is one of the most common extranodal lymphomas with a limited number of published series. We aimed to critically analyze this disease at IPO-Porto, the largest cancer center in Portugal.

A very heterogeneous population was identified, with unspecific clinical signs of disease, which can contribute to diagnostic delay and an advanced disease at presentation. 
Fig. 1 The survival curve according to the Kaplan-Meier method

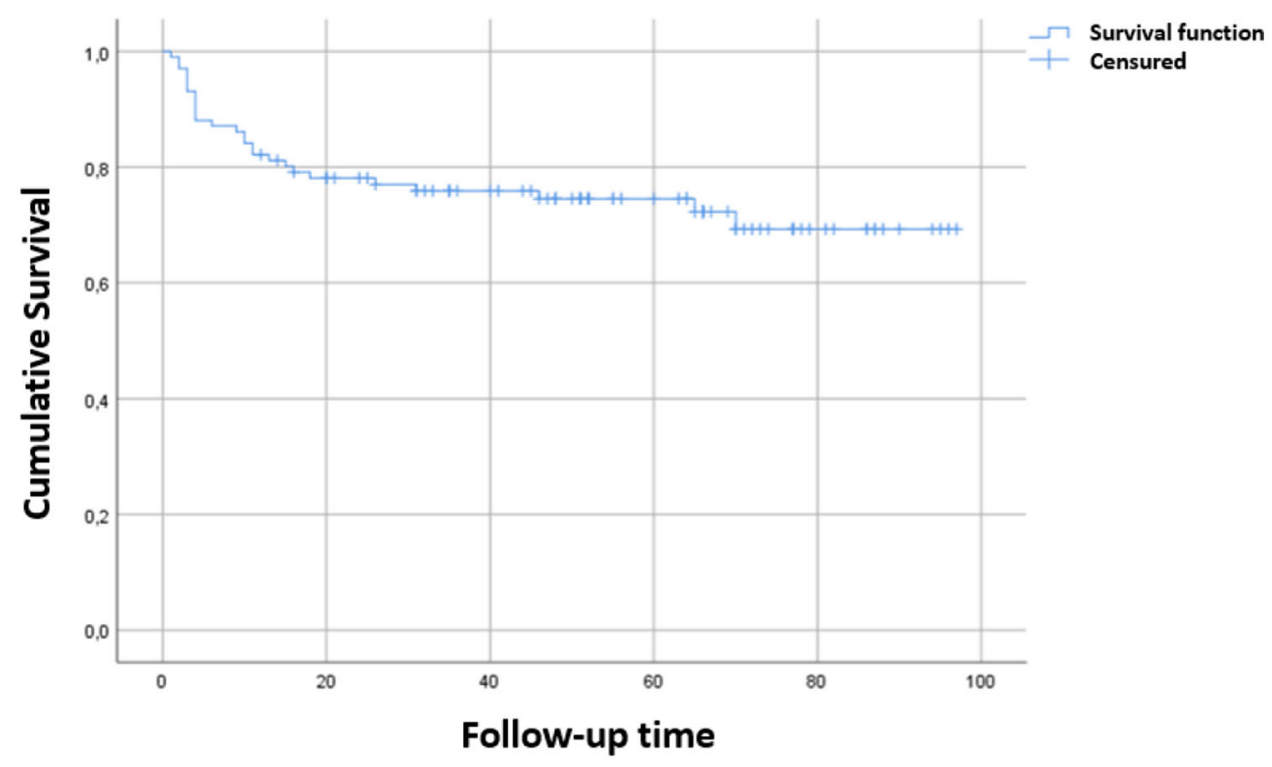

H. pylori infection was depicted in $20 \%$ and all patients received antibiotic therapy in association with chemo/radiotherapy. This target strategy, similar to that used for gastric MALT lymphoma, considers the pathogenesis of the disease [4, 12-14]. Patients carrying $H$. pylori may have better prognosis [5], which we did not confirm.

A few cases were secondary to another lymphoma, mostly MALT and follicular center. This finding is highly dependent on the biopsied material, which can explain the lower incidence when compared with the literature. As expected, the majority of cases were de novo [1].

We did not find significant differences in survival according to Lugano staging, suggesting that R-CHOP-like chemotherapy still is very efficient across all disease stages, after 20 years. Nonetheless, radiotherapy optimized the cure rates for localized disease.

For refractory patients after first line therapy, only $50 \%$ were eligible for intensive treatment, of which $80 \%$ achieved a complete response ( 1 after HSCT). For the other $50 \%, 4$ died before another therapy and 3 achieved a durable complete response. In contrast with oriental series, surgery had a minor role [15].

The most frequent complications identified along treatment were the infections. There were rare cases of gastrointestinal bleeding, perforation or stenosis, probably due to the frailty of the invaded organ.

Although gastric DLBCL is considered an aggressive disease, nearly $73 \%$ of the patients were alive at the end of this study, most of them without disease, suggesting the high efficacy of immunochemotherapy with or without radiotherapy in the long term. Remarkably, the median FU time was superior to 6 years, longer than usually reported in the literature [1-8]. Several parameters were predictive of worse survival in our study, in accordance with the literature [15-18].

The main limitation of this study is its retrospective nature, precluding a more in-depth analysis of factors affecting survival or disclosing predictive value for risk of relapse.

This study adds to the limited number of reports on gastric DLBCL in European populations, contributing to a better understanding of the patient profile and disease biology. Comparatively to cohorts from oriental countries, this population had older patients, higher proportion of females, more advanced disease stage at diagnosis and less surgical interventions [19, 20]. We may conclude that gastric DLBCL is a highly curable disease with R-CHOPlike regimens. Patients who need a second line therapy usually achieve high cure rates when eligible for intensive treatments, whereas the remainder usually endure a poor prognosis.

Funding No financial support received.

\section{Compliance with Ethical Standards}

Conflict of interest The authors have no conflict of interest to declare.

\section{References}

1. Juárez-Salcedo LM et al (2018) Primary gastric lymphoma, epidemiology, clinical diagnosis, and treatment. Cancer Control 25:1-12

2. Parsonnet J, Hansen S, Rodriguez L, Gelb AB, Warnke RA, Jellum E et al (1994) Helicobacter pylori infection and gastric lymphoma. N Engl J Med 330(18):1267-1271 
3. Ferreri AJM, Montalbán C (2007) Primary diffuse large B-cell lymphoma of the stomach. Crit Rev Oncol/Hematol 63:65-71

4. Kuo SH, Yeh KH, Wu MS, Lin CW, Hsu PN, Wang HP, Chen LT, Cheng AL (2012) Helicobacter pylori eradication therapy is effective in the treatment of early-stage $\mathrm{H}$ pylori-positive gastric diffuse large B-cell lymphomas. Blood 119:4838-4844

5. Kuo SH, Yeh KH, Chen LT, Lin CW, Hsu PN, Hsu C, Wu MS, Tzeng YS, Tsai HJ, Wang HP, Cheng AL (2014) Helicobacter pylori-related diffuse large B-cell lymphoma of the stomach: a distinct entity with lower aggressiveness and higher chemosensitivity. Blood Cancer J 4:e220

6. Rackner VL, Thirlby RC, Ryan JA Jr (1991) Role of surgery in multimodality therapy for gastrointestinal lymphoma. Am J Surg 161(5):570-575

7. Tilly H, Gomes da Silva M, Vitolo U, Jack A, Meignan M, Lopez-Guillermo A, Walewski J, André M, Johnson PW, Pfreundschuh M, Ladetto M (2015) Diffuse large B-cell lymphoma (DLBCL): ESMO clinical practice guidelines for diagnosis, treatment and follow-up. Ann Oncol 26(S5):v116-v125

8. Koch P, Probst A, Berdel WE, Willich NA, Reinartz G, Brockmann J et al (2005) Treatment results in localized primary gastric lymphoma: data of patients registered within the German multicenter study (GIT NHL 02/96). J Clin Oncol 23(28):7050-7059

9. Swerdlow SH, Campo E, Harris NL et al (2017) WHO classification of tumors of hematopoietic and lymphoid tissues, 4th edn. IARC Press, Lyon

10. Rohatiner A, d'Amore F, Coiffer B et al (1994) Report on a workshop convened to discuss the pathological and staging classifications of gastrointestinal tract lymphoma. Ann Oncol 5:397-400

11. International Non-Hodgkin's Lymphoma Prognostic Factors Project (1993) A predictive model for aggressive non-Hodgkin's lymphoma. The International Non-Hodgkin's Lymphoma prognosis factor project. NEJM 329:987-994
12. Paydas S (2015) Helicobacter pylori eradication in gastric diffuse large B cell Lymphoma. World J Gastroenterol 21(13):3773-3776

13. Ferreri AJ, Govi S, Raderer M et al (2012) Helicobacter pylori eradication as exclusive treatment for limited-stage gastric diffuse large B-cell lymphoma: results of a multicenter phase 2 trial. Blood 120(18):3858-3860

14. Morgner A, Miehlke S, Fischbach W et al (2001) Complete remission of primary high-grade B-cell gastric lymphoma after cure of Helicobacter pylori infection. J Clin Oncol 19(7):2041-2048

15. Lin JL, Lin JX, Li P, Xie JW, Wang JB, Lu J, Chen QY, Cao LL, Zheng CH, Huang CM (2019) The impact of surgery on longterm survival of patients with primary gastric diffuse large B-cell lymphoma: a SEER population-based study. Gastroenterol Res Pract 2019:9683298

16. Tytgat GN (1998) Helicobacter infection in man: problems to be solved. Dig Dis 16:192-197

17. Godlewski G, Prudhomme M, Pignodel C et al (1997) Double gastric and thyroid localization of MALT lymphoma with lymphocytic thyroiditis. J Chir (Paris) 134:438-441

18. Yoo CC, Levine MS, Furth EE et al (1998) Gastric mucosaassociated lymphoid tissue lymphoma: radiographic findings in six patients. Radiology 208:239-243

19. Kadota $\mathrm{T}$ et al (2019) Complications and outcomes in diffuse large B-cell lymphoma with gastric lesions treated with R-CHOP. Cancer Med 8:982-989

20. Soyer N, Yilmaz AF, Ozsan N, Sahin F, Saydam G, Tombuloglu M, Hekimgil M, Vural F (2017) Retrospective analysis of primary gastric diffuse large B-cell lymphoma: a single center study from Turkey. Turk J Med Sci 47:240-245

Publisher's Note Springer Nature remains neutral with regard to jurisdictional claims in published maps and institutional affiliations. 